\title{
Four different assessment practices: how university teachers handle the field of tension between professional responsibility and professional accountability
}

\author{
Marie Jedemark ${ }^{1} \cdot$ Mikael Londos ${ }^{2}$
}

Published online: 2 September 2020

(c) The Author(s) 2020

\begin{abstract}
Various efforts have been made in higher education in Sweden to meet the demand for more transparent governance and increased efficiency and quality. The purpose of this article is to investigate how university teachers handle standardized models for assessment and examination and orientate in this field of tension between professional responsibility and professional accountability. This study examines school-based courses in teacher education programs at a university and is based on observations from 20 seminars, 10 interviews with university teachers, and 11 focus group interviews with 55 students. The results show that university teachers interpret governing documents in different ways leading to a lack of equivalence. Within one course, four assessment practices are identified: governance as confirmation, governance with need for reinforcement, governance as distrust, and governance as others' responsibility. This study reveals the variation in university teachers' professional assessment practices that challenge and interplay with the context of a curriculum in different ways. Aspects of the university teachers' professional obligation are under tension in the context of a more pronounced accountability. University teachers' professional assessment practices emerges as fragmented in terms of what professional responsibility includes and what professional discretion involves.
\end{abstract}

Keywords Accountability · Assessment - Equivalence · Professional responsibility · Teacher education $\cdot$ University teacher

Mikael Londos

mikael.londos@mau.se

Marie Jedemark

marie.jedemark@mau.se

1 Department of School Development and Leadership, Malmö University, Malmö, Sweden

2 Department of Sport Sciences, Malmö University, Malmö, Sweden 


\section{Introduction}

In recent decades, higher education in Sweden, as in most other European countries, has undergone a series of political reforms. These reforms have intended to meet the demands for increased quality and efficiency and obtain, among other things, greater transparency, a higher degree of standardized documentation, and more comprehensive evaluations (Stensaker \& Harvey 2011; Hansen et al. 2019). An autonomy through collegial decisions based on competence, expertise, and discretion have thus increasingly been replaced by standardized assessments and accountability (Solbrekke \& Karseth 2006). University teachers' right of decision over their own teaching and examination has come to be challenged (Dunn 2014; Evetts 2003; Freidson 2001; Svensson 2010). Solbrekke and Englund (2011) maintain, "the underlying idea is to gain better control over professionals' work by making it more transparent" (p 850). This is to ensure that the professionals are loyal to predefined goals and to accountability (Svensson \& Karlsson 2008; Hansen et al. 2019). Today, universities have to legitimate and communicate their results to the public in more predetermined ways (Solbrekke \& Karseth 2006; Solbrekke \& Sugrue 2014). The control of the education has thereby gradually been transferred from university teachers to officials and politicians and has partly changed the relationship between the professional and the employer. There is a need for further investigation to consider the imposition of accountabilities that are meaningful to the professionals and to the wider society (Broadbent \& Laughlin 1997).

The extended degree of evaluation and control has challenged the university teacher profession (Levin 2017). Consequently, the professionals' understanding of their own role has been gradually shifted and delimited (Brint 1994; Dunn 2014). Previously, the profession's practice was governed from the inside by the professionals, and the regulation of activities was negotiated with the client. Today, the profession is largely governed from the top: from administrators and external reviewers (Evetts 2011; Hansen et al. 2019). Through this increased management of results, the professionals' control over the work is replaced; moreover, their discretionary decision-making is limited, as is their academic freedom. Critique and resistance is de-fused (Davies \& Bansel 2010). McClellend (1990) refers to this change of direction as a move "from within" to "from above," where an autonomy through collegial decisions based on competence, expertise, and discretion has increasingly been replaced with standardized assessments and result reports. Evetts (2009) explains this development with two different contrasting forms of professionalism: organizational professionalism and occupational professionalism. In this study, the first form is represented by the university administration, the managerial leaders at faculty and former university teachers, while the other form is knowledgebased and is and represented by the university teachers. According to Evetts (2009, p. 248), "It is indicative, however, that whereas occupational professionalism emphasizes relationships, organizational professionalism is more dependent on structures." Evetts (2011) asserts that the autonomy given to professionals gives the profession legitimacy and authority. The autonomy is understood by its "outputs" and is rarely possible to standardize and measure. Increased demands for transparency and standardization can also lead to a demand from the professionals for more standardized forms of professional practice, in order to justify their professionalism. Carvalho and Videira (2019) believe that the reason university teachers perceive an increase in administrative control is that their work takes on new modes in administrative processes, even if these seem to be controlled by university teachers themselves. University administrators, here the 
managerial leaders at faculty, see themselves as facilitating academic work (Martimianakis \& Muzzin 2015).

Requirements for transparency with increasingly standardized assessment matrices and examination procedures partly coincide with a focus on student learning strategies in higher education. Studies show that students can spend a lot of time identifying ways to handle and apply requirements connected to the course. Therefore, the assessment itself has a great impact on the students' learning and, in fact, constitutes the actual syllabus. What the students apprehend constitutes the central element of the course and is what they therefore focus on most (Brew et al. 2009; Ramsden, 2003). Segers et al. (2006) point out that the assessment process itself is often based on silent knowledge, does not help students effectively prepare what to study, and forces them to start from contextual "clues," earlier experiences, or pure guesses. Students may not fully understand how assessment decisions are being made and are more skeptical about assessment than the university teachers (Fletcher et al. 2012). Research shows that students need to gain insight into, and understand, the assessment process in order to make the learning process as effective as possible (Fletcher et al. 2012; O'Donovan et al. 2008).

Changes in higher education policy — with its emphasis on accountability, control, and efficiency - have altered the work of university teachers. The university teachers are expected to interpret the context and the requirements for more transparency and uniform practice. University teachers' different approaches to teaching and assessment can be seen in relation to these changes. University teachers' professional approaches depend on curriculum expectations and society's image of the profession, which influences what a university teacher should know and do, based on both their experiences in practice and their backgrounds as university teachers. University teachers' professional approach is an ongoing dynamic process influenced by their involvement in the communities of practices they belong to.

In this article, we want to investigate how university teachers in Sweden-as examiners of students' school-based courses in teacher education - handle the increased demands, decided by officials, from the university on transparency and evaluation through standardized forms of assessment and examination. As examiners, university teachers are expected to make qualified assessments of students' knowledge development at the same time as they are expected to act in accordance with the faculty's local regulations on more standardized assessments and examination processes. In this article, in addition to the question of how university teachers deal with local regulations, we have chosen to study how university teachers in teacher education programs make use of faculty designed governing documents when they assess and examine students in school-based courses. The theoretical aspect of professionalism (Freidson 2001) and the two contrasting forms of professionalism (Evetts 2009) provide a starting point for two opposite logics for professionally performed work as presented by Solbrekke and Englund (2011): professional responsibility and professional accountability. Professional responsibility specifies different meanings of the professional mandate, and professional accountability specifies different meanings of the obligation to report. In this article, we want to highlight how university teachers handle and position themselves between these two steering logics and how these different positions can be understood. 


\section{Purpose}

The purpose of this article is to investigate how university teachers handle standardized models for assessment and examination and orientate in this field of tension between professional responsibility and professional accountability. To achieve this purpose, we formulated two questions:

1 How does the university teacher handle the requirements of standardized assessment documents and conduct the examination prescribed in the faculty's local governing documents?

2 What different assessment practices can be identified, and how can these be understood in relation to the local governing documents?

\section{Local regulation}

We have chosen to study school-based courses in five teacher education programs at a university in Sweden. All other university courses in teacher education programs are proposed and handled by university teachers at the departmental level. However, school-based courses in teacher education programs are proposed and handled by managerial leaders at the faculty office. The faculty has an office that handles and organizes student placement, as well as the introduction program for university teachers involved in school-based courses. This increase in administrative control from the managerial leaders takes on new modes in administrative processes compared to those courses controlled by university teachers at departmental level.

All five teacher education programs comprise the same five courses, each of which is worth 6 credits and for which the students receive graded marks. In these courses, four learning objectives ${ }^{1}$ are formulated around three developmental areas: (1) the ability to analyze and reflect, (2) subject knowledge and didactic competence, and (3) communicative and democratic leadership.

In addition to the syllabus, there are two local steering documents that concern schoolbased courses in teacher education that are proposed by managerial leaders at the faculty office. On the Way to the Teaching Profession is a 30-page booklet that describes the abilities teacher students will gradually develop during their professional training. The booklet includes matrices containing descriptions from the three developmental areas that are intended to be used for self-evaluation, supervision and feedback, assessment, and grading.

\footnotetext{
1 After completing the fifth course, the student should,

1. based on research and experience-based knowledge, be able to critically valuate reflection on his/ her teaching assignment and be able to formulate distinct conclusions for his/her own professional development;

2. based on good subject knowledge and theoretically anchored didactic considerations, be able to independently organize and carry out pedagogical activities/teaching in a dialogical and empathetic manner with children's/students' different interests, abilities, and needs in a distinct focus;

3. be able to communicate with children/students and adults in a responsible and empathetic manner and be able to interact with actors in preschool/school regarding the occupational goals and design;

4. be able to identify his/her own need for additional knowledge and competence based on a valuation of own efforts.
} 
The second local steering document is The Framework, an eleven-page document geared towards producing an equivalent assessment process. The Framework describes tasks students are expected to perform and provides the university teacher examiner with an adequate ground to assess all learning outcomes in each course. The second learning objective, to be able to independently organize and carry out teaching, and the third, to be able to communicate with students are not specified in The Framework to be assessed as a lesson observation by the university teacher. Even though the university teacher is obliged to observe a lesson, in The Framework, a three-part dialogue between the university teacher, the supervisor at the school and the university student, is mentioned as a reflection about the school-based practise. The Framework mention the three-part dialogue but primarily focuses on the first learning objective, which is that the student should be able to critically evaluate reflection on his/her teaching assignment.

The Framework stipulates that at the introductory seminar, the university teacher has to present the course's learning objectives, grading criteria, and examination forms. During the seminar, the students must select one aspect per development area and then give written examples of the knowledge and skills they want to develop in the courses and the strategies they want to use to strengthen their own competence. The text should serve as a support for the students' self-evaluation, which is written at the end of the course and is part of the examination. The text is submitted to the university teacher and supervisor. The examination seminar is conducted on the last day of the course in order to test the students' analytical and reflective ability. Prior to the seminar, the students must have prepared a presentation on a problematic situation drawn from the school activities. The framework document states that the presentation should be linked to both research and own experience as well as to relevant national governance documents. After the presentation, the students must lead a collegial reflective dialogue about the problematic situation.

\section{Data collection}

Education studies involve various complex activities in the form of different courses with different modules, which in turn consist of different parts, such as teaching, assessment, and grading. All of these parts, more or less intertwined, constitute the education program as a whole. These courses and modules can also be referred to as practices. The participants' actions can only be understood in relation to the activity as a whole, and the participants are always a community of multiple points of views, partly because they represent different approaches, traditions, and interests (Chaiklin and Lave 1993; Engeström 2001). What characterizes a practice can be identified by studying what is going on: what is to be accomplished and who does what with help of which tools. Therefore, we have chosen to carry out observations of the courses' introductory seminars as well as the final examination seminars. In addition, we have conducted interviews with the university teacher examiners and group interviews with the students. Studying how different assessment practices are performed also allows us to discuss how university teachers handle local regulations and what characterizes different assessment practices.

The university has five teacher education programs, and each contains five school-based courses consisting of 30 higher education credits in total. In order to gain a wide range of data, we chose to explore two courses within each teacher education program. In total, we have observed in 10 different courses conducted by 10 university teachers. We chose the courses given in the middle or at the end of the program based on the assumption that 
students would have experience from previous school-based courses and would be familiar with the university teachers' way of conducting the examination. The empirical material consists of observations from both the introductory seminars that are conducted 10 days before the course starts and the final examination seminars that are conducted on the last day of the course. The university teachers and the student groups connected to the chosen courses were asked for permission. We recorded the conversations and took notes during the same student group seminars, i.e., both the introductory and the examination seminars. We observed a total of 20 seminars.

After the examination seminar, we conducted a group interview with each student group as well as an interview with all university teacher examiners. In the group interviews, we asked students how they interpreted the task of the examination seminar as described in the local regulations and the examination instructions and also how they made use of various documents. In interviews with university, teachers we asked questions about the seminars and how the regulated tasks work. We also asked the university teachers how they use the local regulations and how they conduct the examination. We subsequently transcribed all the notes/audio files. From five different teacher education programs, we have interviewed 10 experienced university teachers engaged at different departments at the faculty who have been teaching in school-based courses for many years. These university teachers also have experience from teaching in schools at preschool, primary, secondary, or uppersecondary school levels. We also interviewed 55 students in 11 groups from all five teacher education programs.

\section{Theoretical framework and analysis}

In order to observe and evaluate how university teachers handle local governance in relation to their professionalism, we use two different logics. The theoretical background for using these logics comes from Friedson's (2001) work on professionalism and Evetts' (2009) two forms of professionalism: organizational professionalism and occupational professionalism. From these theoretical tools, Solbrekke and Englund (2011) have constructed professional responsibility and professional accountability as analytical tools, which our analysis is based on. With the help of these analytical tools and concepts that implicate the professionalism of university teachers, we can show the consequences for how professional work is carried out and valued. We have adapted and translated the concepts into a university setting that will enable us to identify the field of tension between being professionally responsible and being professionally accountable. Concepts and theories in the analytical process to handle the empirical material are used in a more abductive approach. The methodological considerations that have been made are to try to find patterns and contexts by means of the theoretical concepts in an interpretive analysis of the assessment practice. This means that patterns of different assessment practices become visible in the analysis. Theoretically informed methodology worked here as a kind of analytical tool "to see with" and used to get a grasp of "reality." Constructing different assessment practices allows us to discuss how university teachers handle local regulations in an elaborated way.

\section{Professional responsibility}

Professional responsibility is a concept which embeds responsibility to both clients (students) and public interests, and it relies on both science-based and experienced-based 
knowledge and professional ethics (Freidson 2001). In practice, professional responsibility is given different orientation depending on what is at stake and given priority depending on differences in tradition, policy, and those who are defining it (Solbrekke \& Englund 2011). Acting in a professionally responsible manner can have different meanings in different contexts and in relation to differing expectations and conflicting ideas about best practice. Professional responsibility is based on trust in the professional agent. For example, a university teacher-being qualified to do the job-expects to be able to exercise their professional judgment and deliberate on his or her own or together with colleagues in order to manage potential dilemmas in a professional manner. Professionals should be able to justify their decisions and actions through science and experience-based knowledge and moral considerations. However, an action can rarely be determined in advance and its consequences cannot always be "measured" based on predetermined indicators. Professional responsibility implies a proactive action focus with the professional as initiator and responsible for what is regarded best for both students and society (Solbrekke \& Englund 2011).

\section{Professional accountability}

Accountability is strongly linked to an audit system with both local and external evaluations. From this perspective, high quality relates to accounts towards regulated standards and transparent and explicit assessments. Therefore, accountability requires compliance with regulation and pre-formulated standards. Increased governance implies that politicians and administrative officials have developed models that require increasing transparency, which in turn increases requirements for accountability in the form of documentation from professionals. Unlike professional responsibility, accountability involves explicit standardized contracts and emphasizes the duty of professionals to be able to account for and respond to their actions, which must be checked and evaluated in relation to predetermined criteria. Thus, accountability in this perspective is subject to control top down and it is not primarily about trust as with professional responsibility (Solbrekke \& Englund 2011).

Accountability usually involves a reactive action, an action initiated by others than the professionals and to which the professionals have to report their documentation. The control logic of accountability is based on distinct descriptions in a transparent language that is easily understandable to all "users" because defined reference points means guaranteed quality. It is a form of general management that differs from professional responsibility, which is based on the professional's judgment (Solbrekke \& Englund 2011).

\section{Findings}

In our data, from interviews and observations, we distinguished four qualitatively different ways in which the university teachers handle the local governing documents. The way university teachers handle local governance contributes to the formation of different assessment practices. These assessment practices differ in what university teachers consider as important and how they carry out the assessment. Based on how the university teachers use local regulations, we identified four different assessment practices: (1) governance as confirmation, (2) supplemented governance, (3) governance as distrust, and (4) governance as others' responsibility. 


\section{Governance as confirmation}

In the assessment practice of governance as confirmation, university teachers generally find the local regulations helpful in clarifying the education and creating a structure that increases equivalence. This equivalence is expressed by the fact that the university teachers in this practice carry out the examination in the same way. For some university teachers, the local governance regulations do not mean a big change because the university teachers already carry out the assessment work in line with the local regulations. The local regulations become confirmed when assessment and grading are carried out in a manner expected by the employer. At the introductory seminars, the university teachers inform students that they have to bring documentation to the supervisors at the practice schools as stated in the local regulations. Students receive copies of the local regulations at the introductory seminar and are shown which forms to use and what time to submit them to the university teacher examiner.

In this assessment practice, the university teachers see it necessary to verify that students follow the local regulations, make use of the produced forms, and provide the documentation:

University teacher: The documentation must be available. If the documentation is not submitted, they will not be approved.

Interviewer: Are you checking the content? Or is it more that they have done, that they have filled in the document?

University teacher: It must be completed and included in the overall assessment.

The teachers find that education has been made more equal and visible to students by communicating a "lowest level" in the local regulations, what students are expected to do within the school-based course. Therefore, university teachers can easily motivate to students why certain tasks need to be done. In summary, there is an agreement in the assessment practice between what is prescribed in The Framework and what is being carried out, as well as what university teachers and students perceive as examining parts of the course. The Framework and On the Way are used as templates. University teachers use their role as facilitators to create agreement between how the assessment process is described in local documents and how it is carried out.

\section{Supplemented governance}

In the assessment practice we have labelled supplemented governance, all assessment documents mentioned in The Framework are used. In addition, the university teachers following this practice strengthen the examination process by requiring students to send in additional documents. The teachers make an effort to inform the students about the local regulations and what is applicable, and they ensure that assessment and grading are done according to the local regulations. The teachers use all the control given in the local regulations but do not find these regulations adequate, so the students have to submit additional documentation.

University teacher: They have to send in this on the way ... and then they have to send in a lesson plan two days before I arrive at the lesson I will observe; and then they have to send in a didactic plan. 
The students create and submit up to a total of eleven assessment documents during a 4-week period. The university teachers use assessment matrices from the booklet $O n$ the Way to show students the importance of following the local documents. The matrices are used as a tool to manage the diversity of goals and content that should be assessed:

Student 1: It is a checklist. "What goals have you achieved?" As a student, you have the task of leading the assessment dialogue. Then I say, I think I have achieved this goal. Then the university teacher says, "I also think so. Write it!" Then the university teacher goes on. There is no more said about it.

Student 2: I get very stressed. "Yes I think so, too." "Write it down!" So you sit there and think is this really all I have achieved?

Student 1: Instead of having a freer conversation and maybe talking about what you think you have developed. The assessment dialogue is very shattered. We do not talk about the lesson that I have just completed, but instead, it is the local directives that are central and it will only be check, check.

Student 2: It feels like an unnecessary thing. The university teacher sits during my lesson and ticks off the matrices in On the Way to the Teaching Profession. Instead of lining up plus and minus, there are things we could talk about instead. Have a more fluid dialogue. I think it could have been a better conversation.

Student 1: It is pretty much text. You do not have all the goals in your head. So you have to sit and read from the document.

In summary, the assessment practice supplemented governance is characterized by the need of the university teachers to reinforce The Framework with extra tasks that the students must complete and submit for assessment. Furthermore, the document On the Way is mainly used as a matrix tool for the development areas during both the teachers' assessment and the subsequent assessment dialogue. In this assessment practice, the university teachers become executors who collect and check the students' achievements.

\section{Governance as distrust}

In the assessment practice governance as distrust, university teachers view local governmental directives as the employer's way of creating increased transparency and control and of judging whether the university teachers lack in professionalism:

University Teacher: I do not think that you can formalize things the way they have done here. There is a distrust of us as professionals. A distrust of what we do. They are very governing. I adapt. But I wonder if that is professional. I have certainly in some respects become a worse teacher because I have to adjust [...] Visits made in schools look different now. Sometimes you get to focus on certain things very hard while The Framework says you should do something else.

In this assessment practice, the steering documents have no prominent role as guiding tools. For example, the students in the group interviews confirm that no or only few references are made to The Framework. This indicates that this document is not known by all students. The students appear to perceive it as optional to use the documentation form for the assessment dialogue. Based on their professionalism, the university teachers interpret the local steering documents and decide how they are to be implemented. The university teachers argue that the increased requirements for documentation lead to a shift in focus from dialogue with the students to documentation. Risk documentation thus becomes a 
goal in itself. The university teachers base their examination on the lessons, the assessment dialogue, and the students' self-evaluation. Consequently, the closing seminar does not count as an examination in this assessment practice.

In summary, the assessment practice governance as distrust is characterized by the university teachers using the documents independently and employing professional judgment, which is considered the most important in this assessment process. The way in which the university teachers take a coaching role manifests the distrust in the accountability requirements. The university teachers feel confident in their own ability to make professional assessments.

\section{Governance as others' responsibility}

In the fourth assessment practice, governance as others' responsibility, the university teachers talk about the local steering documents as something that mainly concerns others-the students, the supervisors, and other university teachers.

University teacher: First and foremost, it is very important, and I think that the supervisors should use it. It is there tool for making an assessment. ... I think that we should make the supervisors much more responsible for the students' school-based courses.

The university teachers ignore the two local regulations as they do not find them legitimate. The regulations are not applied by the university teachers, which becomes obvious when the students in a focus group interview are asked how the tasks in the course are carried out:

Interviewer: I would like to hear what you think about these own goals that you formulate.

Student 4: Before or?

Interviewer: Yes.

Student 4: Which we don't have...

Student 3: Do you do that?

Student 2: What goals...?

The assessment practice is characterized by great variation and heterogeneity. The university teachers following this practice conduct the course documentation in other ways than those prescribed in the local regulation-or not at all. In the assessment practice, some university teachers serve as the taskmasters that are linked neither to The Framework nor to On the Way. Other university teachers give the students assignments for discussion that are beyond the purpose of the course. When it comes to the examination seminar, the content varies if it takes place at all. The university teachers point out that the examination seminar rather offers the possibility to exchange experience rather than serve its examining function. Here, the assignment is passed on to the supervisor, who is given great responsibility for the assessment. In summary, this assessment practice is delegated to students as well as to supervisors to manage.

\section{Assessment and examination in school-based courses of teacher education}

Our empirical data and analysis show that assessment and examination are carried out in four qualitatively different ways in the same school-based courses in teacher education. 
As shown, the university teachers relate to and interpret the steering documents in different ways. The various assessment practices are not created within a particular educational program; rather, they seem to correspond to how university teachers perceive their task of assessing and examining the students' professional knowledge in one school-based course. In this study, we have not studied if and how university teachers transform their assessment practices over time in all five school-based courses.

In all observations, the teachers used the introductory seminar mainly to provide information. How detailed is the information given about assessment and examination varies widely between the different assessment practices. Only a minority of university teachers use the introductory seminar to give room for students to discuss, in pairs or in the group, the meaning of the learning outcomes and how they can proceed to achieve them. Assessment practices in the governance as confirmation and governance as others' responsibility can be seen as reactive. The university teacher either strictly obeys the regulations or lets students discover and take responsibility for the implementation of local regulations by themselves. In these assessment practices, the local regulations are not supplemented; they are either followed or ignored. On the other hand, the assessment practices supplemented governance and governance as distrust can be interpreted as proactive because the local regulations are comprehended as deficient: either too extensive and detailed, or inadequate and in need of reinforcement. The university teachers make an active transformation of the governance so it responds to what they find proper as assignments (see Fig. 1).

In two of the assessment practices, governance as confirmation and supplemented governance, local regulations are apprehended as governing in the sense that university teachers initiate assessment and examination based on The Framework and On the Way. Thus, the local regulations are placed in the foreground. The difference between these two assessment practices is that supplemented governance requires students to hand in even more documents than regulated compared to governance as confirmation. When it comes to the assessment practices of governance as distrust and governance as others' responsibility, these two practices are characterized by the fact that university teachers relate to the various regulations independently and local regulations are placed in the background. However, there are also differences between the two assessment practices concerning what parts of the local regulations the university teacher chooses to follow, how these choices are justified, and how extensively the university teacher informs students about the assessments. The university teachers in the assessment practice governance as distrust often refer in the interviews to the local documentations Framework and On the Way, and they are distinct when they choose to disregard the local regulations and motivate their position based on their professional experience and their professional responsibility. The university teachers in the assessment practice governance as others' responsibility rarely or never refer to the local regulations (see Fig. 1).

The interview material shows that the university teachers pay attention to the learning objectives in different ways. This may explain why they value the assessment tasks differently. In the assessment practice governance as confirmation, the university teachers do not place importance on the lesson observation since it is not mentioned at all in the local regulations. Two of the learning objectives: subject knowledge and didactic competence, and communicative and democratic leadership are not thereby examined directly by the university teacher. The university teacher has to lean on a secondary view on practice formulated in the supervisor's judgment. The students' analytical and reflective ability is the only learning objective that is directly examined by the university teacher. Therefore, the examination seminar, the students' self-evaluation, and the supervisor's judgment are most valued in the grading process and are in 


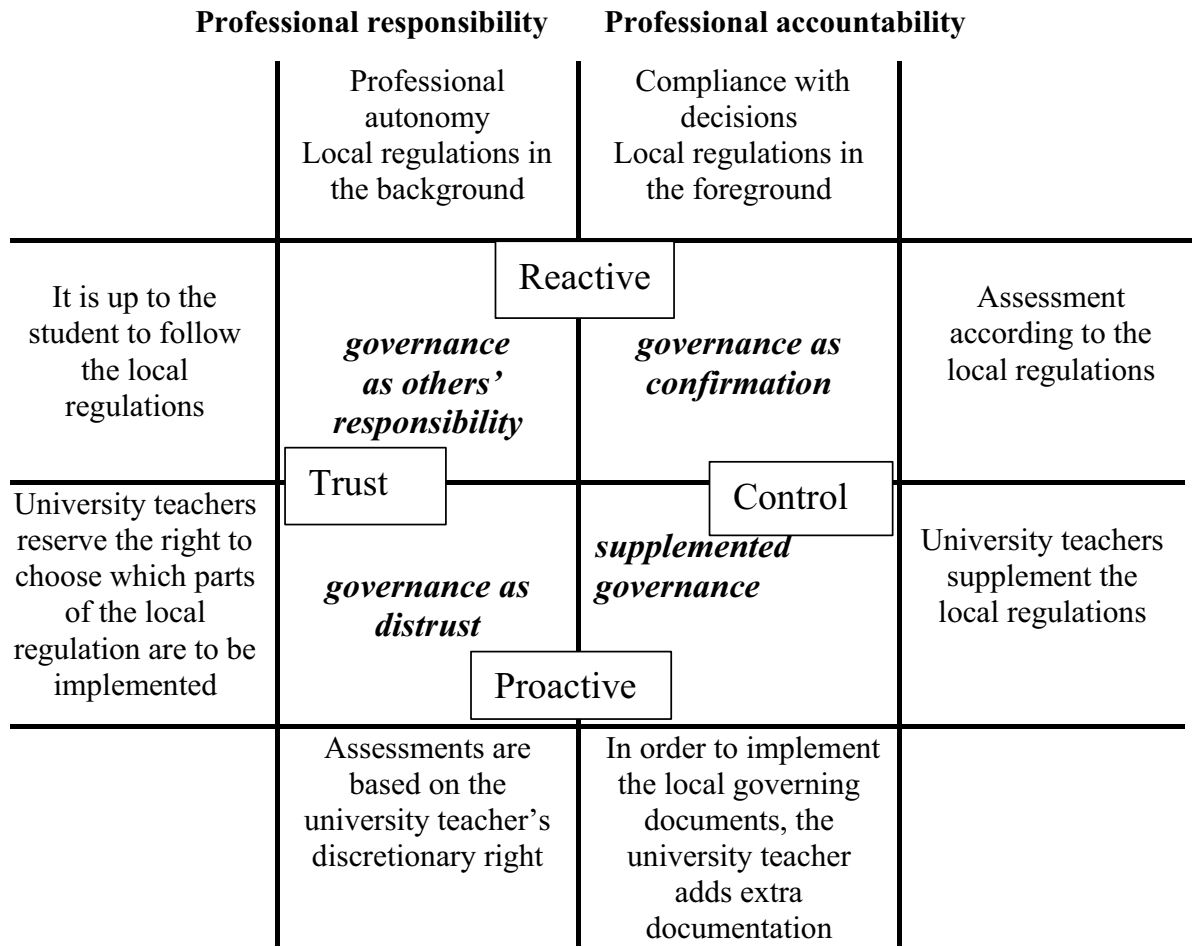

Fig. 1 Comparison of four different assessment practices placed in a field of tension between professional responsibility and professional accountability showing how university teachers are responding to governance in relation to reactive-proactive, trust-control

line with the local regulations. In the assessment practice supplemented governance, extra assessment documentations are used to carry out grading in line with the local regulations. In the focus group interviews, students say that they have higher requirements and more assessment documents to submit compared to what other course mates have to submit. These students say it is unfair, but they also feel they are getting a good education. It is not equivalent to all.

In assessment practice governance as distrust, the focus shifts to the students' ability to plan and lead teaching as well as their ability to reflect on their own teaching practice. The observed student-led lesson and the assessment dialogue the university teacher has together with the student and the supervisor both constitute the most important assessment documents. Other prescribed assignments are given low or no value at all. The assessment practice is characterized by the university teachers having confidence in their own professional ability to make assessments and encouraging students to be critical of the local governing documents. In the assessment practice governance as others' responsibility, few assessment documents are used. In practice, the focus is on how students plan, implement, and reflect on their teaching. Accordingly, only a little time is devoted to inform students at the introductory seminar about the assessment process. The focus group interviews show that some students are unfamiliar with the local regulations and lack knowledge of how the assessment is made. 


\section{Concluding reflections}

Earlier we asked the question, which different assessment practices can we identify in the data material and how can we understand them in relation to the local governing documents? We identified four qualitatively different assessment practices: (1) governance as confirmation, (2) supplemented governance, (3) governance as distrust, and (4) governance as others' responsibility. In the first assessment practice, the documents are seen as a template to follow, and the university teacher acts as a facilitator to check that the students submit the assessment documentation. In the second assessment practice, the documents are used as matrices to be checked out. The university teacher then further strengthens the assessment by giving students extra examination assignments. In the third assessment practice, the university teacher only chooses parts of the documents for the students to apply because he/she distrusts the guidance indicated by the documents. The results show that the students are coached to be able to navigate the assessment bases that the university teacher considers to be valid. In the fourth assessment practice, the university teacher considers that the documents are mainly for others-namely, students, supervisors, and other university teachers. Assessment documents are independently formulated by the university teacher, who acts independently.

We also asked the question, how does the university teacher handle requirements of standardized assessment documents and conduct the examination prescribed in the university's local governing documents? There is a clear tension between how the university teachers interpret and handle the local governing documents. In three out of four assessment practices, the local regulations are actively applied: The university teacher either follows the regulations, chooses to supplement the regulations, or chooses to follow parts of the regulations. In the fourth assessment practice, university teachers choose to ignore the local regulations. The university teachers' approaches to handling the local regulations indicate the tension between the professional responsibility and professional accountability in four different assessment practices.

The lesson observation and three-part dialogues conducted between supervisors, students, and university teachers are highly valued by both the university teachers and the students, and are crucial for the assessment in the school-based course. Though the lesson observation is not mentioned in The Framework, it gives an opportunity for the university teacher to see how the student use didactic and communicative abilities (learning objectives two and three). On the other hand, the three-part dialogue is mentioned in the local regulation as one of the course's assessment forms. The university teacher is the examiner in the school-based course. However, the lesson observation is not mentioned in any document. The lesson observation gives no value that requires verification in the form of assessment documentation. Instead, the lesson observation is handled by the university teacher based on his or her professional judgment and responsibility. The lesson observation in a teacher education is perceived as implicit and up to the university teacher to deal with, when in practice great value is added to the assessment process and corresponds to the syllabus' second and third learning objectives.

In the first assessment practice governance as confirmation, there is no obvious tension between how the assessment process is described in local documents and how it is carried out. University teachers use their role as a facilitator to create agreement in the assessment practice and use The Framework and On the Way as templates. In the second assessment practice supplemented governance indicate a tension between what the university teachers see as necessary to assess in comparison to what is prescribed 
in The Framework. The teachers do not find these regulations adequate, so the students have to submit additional documentation. In the third assessment practice governance as distrust also indicate a tension between what the university teachers consider the most important in this assessment process and what the local regulation indicate. The university teachers base their examination mainly on lesson observation of student teaching. The local regulation does not mention lesson observation as an assessment form. The fourth assessment practice, governance as others' responsibility, indicates an obvious tension between what the university teachers consider important to be carried out in the assessment process and how it is described in local regulations. The university teachers do not see the local regulations as binding. The Framework and On the Way is delegated to students as well as to supervisors to manage.

Many university teachers try to keep their professional objects and routines and transfer them to the new regulations. Others overlook the new requirements, whereas some university teachers reformulate their professional object so that they better respond to the new control system (Levin 2017). How the syllabus as a steering document can be made explicit depending on the extent to which the course's various documents actually reflect the course's content and learning objectives. Dunn (2014) states when university teachers execute the local regulations, their professional autonomy shrinks and university teachers are deskilled by both increased supervision and standardization of their work which decreases opportunities for academic freedom. This study shows that there is a variation of approaches that visualizes the university teachers' professional self-regulated autonomy as different assessment practices. Based on university teachers' professional practices, they interpret these documents and decide in various ways how to manage the course (cf. Hegender 2010, Jedemark 2019). This study shows that there is a tension between what is actually assessed and examined and what the regulation in the steering documents stipulates must be assessed.

The local regulations are meant to clarify the education and create a structure that contributes to increased equivalence, or consistency across teacher and student practices. In the formulation of the extensive local regulations, the education providers express a strong confidence in what is possible to achieve with local regulations. However, this study shows that despite detailed descriptions of how the assessment is to be carried out during the course, qualitatively different assessment practices transpire. What and how students are expected to document during their school-based education largely varies. Similarly, the assessment practices vary between what is being examined and how clearly this is communicated with the students. Despite the goal of increasing transparency and equivalence in local regulations, most students are still unsure about what they are assessed on and what is expected of them during the education. Therefore, the extended control in the form of locally designed regulations has arguably not led to increased equivalence.

We have previously stated that the examination governs the students' learning orientation and constitutes the actual syllabus (Brew et al. 2009; Ramsden, 2003). Students need to gain insight into and understand the assessment process in order to benefit from the course in the best way (Fletcher et al. 2012, Rust et al. 2005). This study shows that some students lack knowledge about the assessment process, while others, within the same course but with another university teacher, know what is required of them. In general, the students express that they do not know how different assessment assignments are weighted together. They speculate on what is actually included in the final grade. This means that students find it difficult to prepare effectively (Segers et al. 2006). Inaccurate and unreliable assessment documentation risks undermining the quality and value of the assessment itself (Fletcher et al. 2012), as well as the value of the dialogues that are conducted between 
supervisors, students, and university teachers. In practice, school-based courses are implicitly governed by several hidden syllabuses.

In order to promote the professionalism of university teachers, it is not enough to reformulate the existing local documents or create additional regulations with increased control of the accountability obligation. Other efforts must be made to enable in-depth knowledge of the educational curriculum and syllabus as well as the assessment process. In the study, we note that the university teachers' professional responsibility to deal with the assessment process is mainly done on their own. We concur with Rust (2007) and Fletcher et al. (2012) who emphasize the need for urgency in the development of a scholarship around issues in higher education assessment. What is missing is a practice, together with colleagues, to handle these situations in a professional way (cf. Freidson 2001, Solbrekke \& Englund 2011).

We pay attention to how increased demands on transparency, standardization, and accountability have changed the governance of professionals (Beck 2008; Broadbent \& Laughlin 1997; Davies \& Bansel 2010). In order to develop meaningful accountabilities, professionals need to come together and find a suitable accountability mechanism through discussion (Broadbent \& Laughlin 1997). To achieve this, meetings and discussions need to take place at the departmental level and involve university teachers' views on assessment and examination.

The major contribution from this study-which is not found in other research about changes in governance of teaching professions - is that we focus on and reveal the variation in university teachers' professional assessment practices that challenge and interplay with the context of a curriculum in different ways. Aspects of the university teachers' professional obligation are under tension in the context of a more pronounced accountability. University teachers' professional assessment practices emerges as fragmented in terms of what professional responsibility includes and what professional discretion involves. Professional autonomy and discretion are not something that university teachers either have or do not have; rather, they are something they use to make sense of themselves as university teachers. That is, they combine the use of autonomy and discretion to balance different parts of their professional assessment practices.

Funding Open access funding provided by Malmö University.

Open Access This article is licensed under a Creative Commons Attribution 4.0 International License, which permits use, sharing, adaptation, distribution and reproduction in any medium or format, as long as you give appropriate credit to the original author(s) and the source, provide a link to the Creative Commons licence, and indicate if changes were made. The images or other third party material in this article are included in the article's Creative Commons licence, unless indicated otherwise in a credit line to the material. If material is not included in the article's Creative Commons licence and your intended use is not permitted by statutory regulation or exceeds the permitted use, you will need to obtain permission directly from the copyright holder. To view a copy of this licence, visit http://creativecommons.org/licenses/by/4.0/.

\section{References}

Beck, J. (2008). Governmental professionalism: Re-professionalising or de-professionalising teachers in England. British Journal of Educational Studies, 56(2), 119-143.

Brew, C., Riley, P., \& Walta, C. (2009). Education students and their teachers: Comparing views on participative assessment practice. Assessment \& Evaluation in Higher Education, 34(6), 641-657.

Brint, S. (1994). In an age of experts. Princeton, NJ: Princeton University Press. 
Broadbent, J., \& Laughlin, R. (1997). Accounting logic' and controlling professionals. In J. Broadbent, M. Dietrich, \& J. Roberts (Eds.), The end of professions? The Restructuring of Professional Work: Routledge.

Carvalho, T., \& Videira, P. (2019). Losing autonomy? Restructuring higher education institutions governance and relations between teaching and non-teaching staff. Studies in Higher Education, 44(4), $762-773$.

Chaiklin, S., \& Lave, J. (1993). Understanding practice: Perspectives on activity and context. Cambridge, MA: Cambridge University Press.

Davies, B., \& Bansel, P. (2010). Governmentality and academic work: Shaping the hearts and minds of academic workers. Journal of Curriculum Theorizing, 26(3), 5-20.

Dunn, Mary (2014) An institutional ethnographic investigation of college professors' experiences constructing course outlines. PhD Thesis, OISE/UT.

Evetts, J. (2003). The sociological analysis of professionalism. Occupational change in the modern world. International Sociology, 18(2), 395-415.

Evetts, J. (2009). New Professionalism and New Public Management: Changes, Continuities and Consequences. Comparative Sociology, 8(2), 247-266.

Evetts, J. (2011). Sociological analysis of professionalism: past, present and future. Comperative Sociology, 10, 1-37.

Engeström, Y. (2001). Expansive learning at work: Toward an activity theoretical reconceptualization. Journal of Education and Work, 14(1), 133-156.

Fletcher, R. B., Meyer, L. H., Anderson, H., Johnston, P., \& Rees, M. (2012). Faculty and students conceptions of assessment in higher education. Higher Education, 64(1), 119-133.

Freidson, E. (2001). Professionalism. The Third Logic. Cambridge: Polity Press.

Hansen, H. F., Geschwind, L., Kivistö, J., Pekkola, E., Pinheiro, R., \& Pulkkinen, K. (2019). Balancing accountability and trust: university reforms in the Nordic countries. Higher education, 78(3), $557-573$.

Hegender, H. (2010). The assessment of student teachers' academic and professional knowledge in school-based teacher education. Scandinavian Journal of Educational Research, 54(2), 151-171.

Jedemark, M. (2019). A scientific approach in the assessment of the school-based part of the teacher education programme in Sweden. Journal of Curriculum Studies, 51(3), 420-436.

Levin, J. (2017). Community colleges and new universities under neoliberal pressures. New York: Palgrave Macmillan. Springer Nature.

Martimianakis, M. A., \& Muzzin, L. (2015). Discourses of interdisciplinarity and the shifting topography of academic work: generational perspectives on facilitating and resisting neoliberalism. Studies in Higher Education., 40(8), 1454-1470.

McClellend, C. E. (1990). Escape from freedom? Reflections on German professionalization 1870-1933. In M. Burrage \& R. Torstendahl (Eds.), The Formation of Professions: Knowledge, State and Strategy (pp. 97-113). London: Sage.

O’Donovan, B., Price, M., \& Rust, C. (2008). Developing student understanding of assessment standards: a nested hierarchy of approaches. Teaching in Higher Education, 13(2), 205-217.

Ramsden, P. (2003). Learning to teach in higher education (2nd ed.). London: Routledge.

Rust, C. (2007). Towards a scholarship of assessment. Assessment and Evaluation in Higher Education, 32(2), 229-237.

Rust, C., O’Donovan, B., \& Price, M. (2005). A Social Constructivist Assessment Process Model: How the Research Literature Shows Us This Could Be Best Practice. Assessment and Evaluation in Higher Education, 30(3), 231-240.

Segers, M., Nujhuis, J., \& Gijselaers, W. (2006). Redesigning a learning and assessment environment: the influence on students' perceptions of assessment demands and their learning strategies. Studies in Educational Evaluation, 32(3), 223-242.

Solbrekke, T. D., \& Englund, T. (2011). Bringing professional responsibility back in. Studies in Higher Education, 36(7), 847-861.

Solbrekke, T. D., \& Karseth, B. (2006). Professional responsibility - an issue for higher education? Higher Education, 52(1), 95-119.

Solbrekke, T. D., \& Sugrue, C. (2014). Professional accreditation of initial teacher education programmes: Teacher educators strategies-between "accountability" and "professional responsibility"? Teaching and Teacher Education, 37, 11-20.

Stensaker, B., \& Harvey, L. (2011). Accountability in higher education: Global perspectives on trust and power. Abingdon, New York: Routledge. 
Svensson, L. (2010). Professions, organizations, collegiality and accountability. In L. Svensson \& J. Evetts (Eds.), Sociology of professions. Continental and Anglo-Saxon traditions (pp. 145-166). Göteborg: Daidalos.

Svensson, L., \& Karlsson, A. (2008). Profesjon og organsisasjon [Profession and organisation]. In A. Molander \& L. I. Terum (Eds.), Profesjonsstudier [Studies of professions] (pp. 130-141). Oslo: Universitetsforlaget.

Publisher's Note Springer Nature remains neutral with regard to jurisdictional claims in published maps and institutional affiliations. 